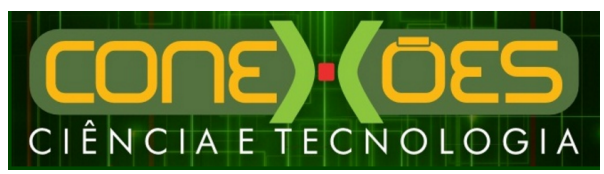

FORMAÇÃO PROFISSIONAL NA SOCIEDADE ATUAL: ACEPÇÕES DOS PROTAGONISTAS DO CURSO TÉCNICO EM SEGURANÇA DO TRABALHO DO IFCE NA MODALIDADE A DISTÂNCIA

\title{
FORMAÇÃO PROFISSIONAL NA SOCIEDADE ATUAL: ACEPÇÕES DOS PROTAGONISTAS DO CURSO TÉCNICO EM SEGURANÇA DO TRABALHO DO IFCE NA MODALIDADE A DISTÂNCIA
}

\author{
Neidimar Lopes Matias de PAUla ${ }^{1}$ \\ ${ }^{1}$ Instituto Federal de Educação, Ciência e Tecnologia do Ceará (IFCE) \\ <neidimar@ifce.edu.br>
}

DOI: $10.21439 /$ conexoes.v12i3.1273

\begin{abstract}
Resumo. A Educação Profissional também concebida como Formação Profissional, ao longo do tempo, tem sido conceituada como aquela que se relaciona com o ensino de um ofício ou profissão e visa à construção de conhecimentos essenciais à preparação de profissionais qualificados e competentes em diferentes áreas de atuação. O presente texto configura-se como um recorte da dissertação de Mestrado em Educação Brasileira pela UFC em abril de 2014 e tem como objetivo apresentar a percepção dos alunos, professores e tutores do Curso Técnico em Segurança do Trabalho do IFCE na modalidade EaD, sobre a Formação Profissional na sociedade atual, confrontando essa percepção com os autores consultados ao longo da pesquisa. Metodologicamente, assume a forma de Estudo de caso com abordagem qualitativa, cuja coleta de dados se deu por meio das técnicas de observação participante, questionário e entrevista. Os sujeitos pesquisados foram: sete alunos, cinco tutores, três professores e o coordenador Geral do Curso Técnico em Segurança do Trabalho do IFCE. Os resultados apontam que a Formação Profissional na sociedade atual está diretamente associada ao papel da instituição escolar como agente formador. Entre outras contribuições, o estudo possibilitou refletir sobre as políticas mais recentes em torno da Educação Profissional no Brasil.
\end{abstract}

Palavras-chaves: Formação Profissional. Instituição escolar. Trabalho. Sociedade atual.

\section{VOCATIONAL TRAINING IN THE CURRENT SOCIETY: ACCEPTIONS OF THE PROTAGONISTS OF THE TECHNICAL COURSE IN THE FIELD OF IFCE WORK IN THE DISTANCE MODE}

\begin{abstract}
The Vocational Education Training also conceived as, over time, has been conceptualized as one that relates to the teaching of a trade or profession and aims to build essential to the preparation of qualified and competent professional knowledge in different areas. This text appears as an indentation of the Master's thesis in Education from the Brazilian UFC in April 2014 and aims to present the perceptions of students, teachers and guardians of the Technical Course in Occupational Safety IFCE in the distance education mode on the training in current society, confronting this perception with the authors consulted during the research. Methodologically, takes the form of case study with a qualitative approach, which data collection was through the techniques of participant observation, questionnaire and interview. The subjects studied were: seven students, five tutors, three teachers and the general coordinator of the Technical Course in Occupational Safety from IFCE. The results show that the Vocational Training in current society, for these subjects, is directly related to the role of the school as a chelating agent. Among other contributions, the study enabled us to reflect on the latest policies around the Vocational Education in Brazil.
\end{abstract}

Keywords: Vocational Training. School institution. work. Current society. 


\section{INTRODUÇÃO}

A Educação Profissional - EP- também concebida como Formação Profissional, ao longo do tempo, tem sido conceituada como aquela que se relaciona com o ensino de um ofício ou profissão e visa à construção de conhecimentos essenciais à preparação de profissionais qualificados e competentes em diferentes áreas de atuação. Numa acepção mais ampla, entende-se que a EP refere-se a todos os processos educativos capazes de levar o indivíduo a desenvolver conhecimentos e habilidades para aplicar no meio produtivo. Esse conhecimento pode ser adquirido tanto na escola formal, como nos ambientes de trabalho.

$\mathrm{Na}$ esfera mundial, o advento do capitalismo e da modernidade fez surgir a figura do trabalhador assalariado, gerando, então, uma demanda por operários qualificados para as muitas atividades emergentes no mundo moderno. O trabalho, a partir daí, passa a ser visto sob novas perspectivas, nas quais se faz necessária uma formação da classe operária que possibilite a aquisição de conhecimentos teóricos e operacionais, garantindo, assim, a produção de bens e serviços condizentes com o desenvolvimento econômico e social.

Tal formação surge a partir da vinculação estabelecida entre a educação escolar e o mundo do trabalho. A escola, então, passou a ser entendida como espaço de transmissão de saberes, assumindo em nível mundial, diferentes papéis em relação ao mundo do trabalho, ou seja, ora servindo de adestradora de mão de obra, ora propondo uma formação integral para os indivíduos ou ainda atuando na perspectiva dualista, com um ensino profissionalizante para os filhos da classe operária e um ensino propedêutico para as elites (KRUPPA, 2005 p. 3).

No Brasil, a formação profissional tem mais de um século de existência, porém o termo "Educação Profissiona" passa a ter força a partir da Lei de Diretrizes e Bases da Educação Nacional - LDB 9394/96 que traz como finalidade dessa modalidade de ensino criar cursos que favoreçam o acesso de estudantes e profissionais de modo geral ao mundo do trabalho. De acordo com o Art. 39 da referida lei, a "Educação Profissional, integrada às diferentes formas de educação, ao trabalho, à ciência e à tecnologia conduz ao permanente desenvolvimento de aptidões para a vida produtiva". Com base no que afirma essa lei, vários programas e políticas públicas têm sido implantados, visando ao suprimento das demandas existentes no mercado profissional brasileiro.

Desse modo, a preocupação com a qualidade da educação, que vem sendo discutida para qualificar o trabalhador brasileiro, tem permeado o campo da pesquisa nessa área, com vistas a encontrar possibilidades reais para a tão necessária transformação social.

Nesse esteio, apresentamos o presente estudo, configurando-o como um recorte de uma pesquisa mais ampla para o curso de Mestrado em Educação Brasileira na Universidade Federal do Ceará, concluído em abril de 2014, cuja investigação limitou-se ao curso Técnico em Segurança do Trabalho do IFCE, na modalidade a Distância. A escolha por essa modalidade se deu pelo desejo de desmistificar alguns preconceitos sobre a Educação a Distância. Convive-se com uma ideia social de que a qualidade da educação brasileira nessa modalidade deixa muito a desejar. Para esta construção tomamos como questão norteadora de uma das categorias analisadas no texto da dissertação, a seguinte pergunta: Como os sujeitos envolvidos na Educação Profissional do curso Técnico em Segurança do Trabalho do IFCE na modalidade a Distância percebem a Formação Profissional na sociedade atual?

Desse modo, com o objetivo de apresentar a percepção dos alunos, professores e tutores do Curso Técnico em Segurança do Trabalho do IFCE sobre a Formação Profissional na sociedade atual, construímos o presente texto. Apresentamos em sua estrutura uma parte introdutória, uma breve discussão teórica, a metodologia usada para as investigações, a análise dos resultados obtidos e, por fim, algumas conclusões expostas nas considerações finais.

\section{A EDUCAÇÃO PROFISSIONAL NO BRASIL: UMA VISÃO DO CONTEXTO}

Estudos relacionados às atuais transformações políticas ou socioeconômicas alertam para as mudanças assentadas em novas bases tecnológicas que exigem formação capaz de responder aos desafios do mundo contemporâneo (KRUPPA, 2005, LIMA, 2005, FRIGOTTO 1996). As políticas públicas, por meio de reformas educacionais, buscam responder às questões e exigências do processo de globalização e, sobretudo, atender às necessidades do setor produtivo.

Em meio a essas políticas e reformas, uma realidade paradoxal caracteriza o nosso contexto socioeconômico em pleno século XXI. Falamos do fato de o Brasil ser um país continental, marcado pela $85^{\mathrm{a}}$ posição no IDH - Índice de Desenvolvimento Humano, contrastando com a $7^{\mathrm{a}}$ posição do PIB no ranking das maiores economias no final de 2012 1 Essa realidade contribui de forma efetiva para ampliarmos as reflexões sobre a educação brasileira, uma vez que acreditamos que o desen-

${ }^{1}$ Dados conforme Revista Veja on-line de 01/03/2013. Disponível em: <http://veja.abril.com.br/noticia/economia/ pib-de-2012-confirma-queda-do-brasil-no-ranking-das-maiores-economias > 
FORMAÇÃO PROFISSIONAL NA SOCIEDADE ATUAL: ACEPÇÕES DOS PROTAGONISTAS DO CURSO TÉCNICO EM SEGURANÇA DO TRABALHO DO IFCE NA MODALIDADE A DISTÂNCIA

volvimento de uma nação somente se constrói de forma sólida se dispõe de comprovada qualidade no seu sistema educacional.

Infelizmente, ainda convivemos com crianças fora da escola, jovens analfabetos e muitos outros analfabetos funcionais, além do paradoxo no campo da produção, onde de um lado há muitos procurando um trabalho e não encontram e, de outro, há muitas vagas ociosas no mercado, por falta de mão de obra qualificada. Na educação, apesar da Constituição Federa $2^{2}$ garantir esse direito a todos, muitos ainda não conseguem estudar porque precisam trabalhar (mesmo sem qualificação) para garantirem sua sobrevivência.

A Educação Profissional, em meio a esse cenário, surge como uma possibilidade de superar a lacuna existente entre as demandas produtivas e a qualificação pessoal decorrente dessas demandas. Segundo Pacheco (2012), este é um

tema de particular interesse para jovens e adultos trabalhadores que esperam uma formação capaz de inseri-los no mundo do trabalho e de leválos a compreender as questões relativas a emprego/desemprego, formação e trabalho e os processos econômicos e sociais em curso no mundo atual (p. 7).

Corroborando esse pensamento, acreditamos que a formação profissional com esses moldes deve necessariamente passar pelo âmbito da instituição escola. Para isso, é útil lembrar que a partir da promulgação da Lei 9394/96, foram aprovados inúmeros pareceres e resoluções que visam aos ajustes necessários ao pleno desenvolvimento dessa modalidade de ensino na Educação Brasileira, alguns dos quais serão mencionados no decorrer desse texto.

Nos últimos quatro séculos de história tornou-se evidente uma relação direta entre trabalho e capital. A conhecida abolição da escravidão ocorreu pela necessidade de trabalhadores disponíveis que vendessem seu tempo de trabalho aos detentores dos instrumentos e dos meios de produção. Desde então, o trabalho tem sofrido inúmeras mudanças a partir de suas imbricações com o capital. E essas mudanças, segundo alguns pesquisadores "saem do trabalho autônomo e independente, para o assalariado, dependente e controlado pelo capital" (LIMA; ALCOFORADO; MARINELLI, 2012).

Nesse contexto, o trabalho, sobretudo o assalariado, assume, entre outras, uma característica de fragmentação e desqualificação profissional, o que demanda uma

\footnotetext{
${ }^{2}$ Conforme Art. 205, "a educação, direito de todos e dever do Estado e da família, será promovida e incentivada com a colaboração da sociedade, visando ao pleno desenvolvimento da pessoa, seu preparo para o exercício da cidadania e sua qualificação para o trabalho"
}

intrínseca relação entre escola e trabalho na perspectiva de articular ações que visam à qualificação das pessoas para o mundo produtivo.

Segundo Oliveira (2005), a escola, por sua vez, exerce a função de transmitir os conhecimentos mínimos necessários à produção e, ao mesmo tempo, desempenha um serviço ideológico reprodutivo que permite justificar as desigualdades sociais. Sob esta ótica, está o entendimento de que quanto mais conhecimento se adquirir na escola, maior será a possibilidade de conseguir um trabalho que renda não só um salário melhor, mas também um prestígio social diferenciado. Desta maneira, autora supracitada assume que "a escola contribui para manter a aparência enganosa de que a hierarquização no trabalho está relacionada ao volume de estudos acumulados por cada um" (p. 75).

De todo modo, a expansão dos meios de produção gerou a necessidade da universalização da escola como agente social de preparação para a inserção no mundo do trabalho. Os processos de modernização tecnológica e organizacional têm-se configurado de diversas formas nas sociedades que compõem o cenário do capitalismo mundial (LIMA; ALCOFORADO; MARINELLI, 2012). E a educação formal torna-se praticamente uma necessidade básica do trabalhador "à medida que parece funcionar como mecanismo de mobilidade social e de acesso ao emprego, em ascendência vertical, na escala hierárquica dentro da empresa" (OLIVEIRA, 2005, p. 76).

Sob essa conjuntura, a educação profissional, no mundo contemporâneo toma forma, sobretudo, na década de 90 e, no Brasil, após a instituição da LDB 9394/96, cuja regulamentação se deu pelo Decreto $\mathrm{N}^{\mathrm{o}}$ 2.208/97, de 17 de abril de 1997. Com esse Decreto se efetivou a Reforma da Educação Profissional no Brasil, gerando muita polêmica entre "os setores educacionais vinculados ao campo da educação profissional, principalmente no âmbito dos sindicatos e dos pesquisadores da área trabalho e educação", por instituir a separação entre o ensino médio e a formação profissional (PACHECO, 2012, p. 27).

Tecendo uma crítica ao modelo que foi implantado a partir da aprovação do referido decreto, Oliveira (2005) afirma ser incoerência separar o ensino médio do técnico, uma vez que a própria LDB estabelece no seu artigo 36 que "o ensino médio, atendida à formação geral do educando, poderá prepará-lo para o exercício de profissões técnicas" (BRASIL, 2011, p. 30).

Nessa mesma direção, Pacheco (2012) relata a reação dos movimentos sociais a essa separação entre educação básica e educação profissional, cujas críticas ao Decreto por parte desses movimentos ocorreram princi- 
FORMAÇÃO PROFISSIONAL NA SOCIEDADE ATUAL: ACEPÇÕES DOS PROTAGONISTAS DO CURSO TÉCNICO EM SEGURANÇA DO TRABALHO DO IFCE NA MODALIDADE A DISTÂNCIA

palmente através das Conferências Nacionais de Educação organizadas pelo Movimento de Defesa da Educação Pública e nos eventos promovidos pelas Comissões de Educação da Câmara de Deputados e do Senado, onde se defendia uma proposta de educação nos moldes das experiências desenvolvidas pelas centrais sindicais e pelos sindicatos dos trabalhadores. Nessas experiências, entrelaçava-se a educação profissional ao ensino fundamental e ao ensino médio, numa perspectiva de formação integral e, a partir de 2003, estas serviram de base para a implementação de vários programas de Educação de Jovens e Adultos - EJA - integrada à Educação Profissional e Técnica - EPT.

Com tantas mobilizações que se instalaram no país em favor de um novo modelo de EPT, em 2004 o Decreto 2.208/97 foi revogado, sendo substituído pelo Decreto 5.154/2004, período que coincide com os primeiros anos do governo Lula o qual, vislumbrando novas perspectivas para a formação do trabalhador brasileiro, implementou políticas na área educacional que, segundo Pacheco (2011, p. 7), "se contrapõem às concepções neoliberais e abrem oportunidades para milhões de jovens e adultos da classe trabalhadora".

Nesse sentido, o Decreto 5.154/2004 foi um instrumento da reforma que sinalizou uma melhor integração entre a Educação Profissional Tecnológica e o setor produtivo, conferindo à EPT o papel social de contribuir com a modernização e o desenvolvimento do país. Em consonância com esse pressuposto, o Programa de Expansão da Educação Profissional - PROEP/MEC (BRASIL, 2004b, p. 47) estabelece que a organização da Educação Profissional e Tecnológica

\section{[...] exige flexibilidade e autonomia e que esteja vinculada ao projeto de desenvolvimento econô- mico e social assumido pelo governo, com vistas a atender à diversidade de situações da população brasileira e contribuir para a redução das desigual- dades sociais; incorporar a discussão da subjetivi- dade e do trabalho, a fim de que se valorizem os sa- beres construídos pelos trabalhadores e eles sejam considerados como sujeitos criativos do trabalho.}

Sob essa perspectiva, é empreendida a busca por uma nova compreensão do currículo que deve direcionar a Educação Profissional e, nesse sentido, importantes considerações são feitas por Moraes, Dias e Nascimento (2004), afirmando que a Educação Profissional deve ser regida tanto por princípios gerais comuns à educação básica, tais como: "flexibilidade, autonomia, igualdade, ética e estética”, como por princípios específicos, próprios da Educação Profissional. As autoras destacam, dentre estes princípios específicos, os seguintes: "competências e laboralidade, flexi- bilidade, interdisciplinaridade e contextualização, identidade dos perfis profissionais de conclusão, autonomia da escola e atualização permanente dos cursos e currículo". Esses princípios têm como base o "aprender a aprender, competência fundamental para inserção do trabalhador numa dinâmica social que se reorganiza permanentemente" (MORAES; DIAS; NASCIMENTO, 2004, p. 178-179).

No que se refere ao processo ensino-aprendizagem na Educação Profissional, os dispositivos legais que regulamentam tal modalidade trazem em sua essência a pedagogia das competências ${ }^{3}$, ancorando nesta, o modelo ideal de educação capaz de integrar ciência e cultura, tecnologia e humanismo, com vistas ao pleno desenvolvimento das potencialidades humanas. Tal pedagogia, defendida, inicialmente, pelas Diretrizes Curriculares do Ensino Médio (Parecer CEB no 15/1998 e Resolução $n^{\circ} 3 / 1998$ ) prega o desenvolvimento de uma "formação básica, de caráter geral e sólido, assentada no desenvolvimento de competências e habilidades do aluno, como melhor meio de preparação para a vida, para a cidadania e para o trabalho" (VIROTE, 2009. p. 74).

Assim, conforme o Decreto 5.154/2004, a Educação Profissional Técnica de Nível Médio deve ser articulada com o ensino médio. Tal articulação deve-se dar de forma integrada, concomitante ou subsequente. Para a obtenção do diploma de técnico de nível médio, o aluno deve concluir seus estudos de educação do ensino médio e profissional técnico de nível médio. Dessa forma, todos os alunos que participam de cursos vinculados ao Sistema e-Tec Brasil, necessariamente, devem ter concluído o ensino médio.

Sendo um curso da rede e-Tec Brasil o campo de investigação deste trabalho, convém definir o e-Tec Brasil. Trata-se de um sistema de Escola Técnica Aberta que funciona na modalidade de educação à Distância. Foi instituído pelo Ministério da Educação, por meio da Secretaria de Educação a Distância (SEED) e a Secretaria de Educação Profissional e Tecnológica (SETEC), dando sequência ao Plano de Desenvolvimento da Educação, no âmbito da política de expansão à educação profissional.

Criado por meio do DECRETO No 6.301 de 12 de dezembro de 2007, este, revogado pelo DECRETO DE $\mathrm{N}^{\mathrm{o}} 7.589$, de 26 de outubro de 2011, visa ao desenvolvimento da educação profissional técnica na modalidade de Educação à Distância, com a finalidade de expandir e democratizar a oferta de cursos técnicos de nível médio, especialmente para o interior do País e para a pe-

\footnotetext{
${ }^{3}$ Teoria presente na obra: PERRENOUD, Philippe. Construir as competências desde a escola. Porto Alegre: Artes Médicas, 1999.
} 
FORMAÇÃO PROFISSIONAL NA SOCIEDADE ATUAL: ACEPÇÕES DOS PROTAGONISTAS DO CURSO TÉCNICO EM SEGURANÇA DO TRABALHO DO IFCE NA MODALIDADE A DISTÂNCIA

riferia das áreas metropolitanas, como também permitir a capacitação profissional inicial e continuada para os estudantes matriculados e para os egressos do ensino médio. Busca, ainda, contribuir para o ingresso, permanência e conclusão do ensino médio dos estudantes da Educação de Jovens e Adultos (CATAPAN; KASSICK; OTERO, 2011).

Os procedimentos metodológicos utilizados na realização da pesquisa que originou esse trabalho são detalhados no tópico seguinte.

\section{METODOLOGIA}

A pesquisa que originou o presente texto configurouse como Estudo de Caso Intrínseco. Segundo Gil (2010), o caso intrínseco é selecionado quando o pesquisador deseja conhece-lo em profundidade sem se preocupar com o desenvolvimento de qualquer teoria. Quanto à sua forma de abordagem, a pesquisa configurou-se como qualitativa. Esta, segundo Bogdan e Biklen (1994), permite uma investigação minuciosa do objeto, onde tudo tem potencial para constituir uma pista que nos ajuda a compreender de forma mais aprofundada o objeto investigado.

Centrada no processo educativo, a investigação contou com o uso das técnicas de observação participante, questionário, análise documental e entrevista. Os sujeitos pesquisados foram: sete alunos, cinco tutores, três professores e o coordenador Geral do Curso Técnico em Segurança do Trabalho do IFCE. Os professores foram investigados por meio de um questionário, os alunos, através de um grupo focal e o coordenador, por meio de uma entrevista semiestruturada. A pesquisa ocorreu no período de dezembro de 2012 a outubro de 2013.

Após a coleta de dados, os achados foram submetidos à análise de conteúdo, a qual, de acordo com Marconi e Lakatos (2001, p. 29) "leva em consideração as significações (conteúdos), sua forma e a distribuição desses conteúdos e formas". Vejamos a seguir, a análise dos dados que geraram a construção desse texto.

\section{ANÁLISE DOS DADOS}

Conforme dito anteriormente, a Formação Profissional na sociedade atual constituiu a primeira, entre as três categorias analisadas por ocasião da pesquisa realizada durante o curso de Mestrado na Universidade Federal do Ceará, concluída em abril de 2014. Antes, porém, vale dizer que entendemos a formação profissional na sociedade atual como algo que vai além da racionalidade técnica, do desenvolvimento da competência laboral, a serviço de um sistema capitalista. Para nós, formar devidamente o profissional nos dias atuais requer um modelo de educação que possibilite tanto o 'aprender a fazer' como o desenvolvimento integral do educando. Requer, portanto, uma educação socialmente inclusiva e emancipadora na qual os homens possam construir sua cidadania.

Ilustramos esse pensamento com as ideias de $\mathrm{Pa}$ checo (2011), que propõe um modelo de educação comprometido com a emancipação daqueles que vivem à margem de nossa sociedade; uma educação na qual se tenha como premissa o conceito de inclusão, possibilitando aos excluídos a sua emancipação humana e social. Dessa forma é possível construir também os princípios básicos da cidadania como consciência, organização e mobilização, ou seja, uma educação que transforme o educando em sujeito da história.

Nessa mesma direção Freire (2005, p. 80), em oposição à educação tradicional, denominada por ele de “educação bancária," apresenta uma pedagogia problematizadora, na qual o educando é instigado a refletir sobre problemas de sua realidade. Para este autor, quanto mais se desafia os educandos, mais estes compreendem o desafio na própria ação de captá-lo. Nessa perspectiva, defendemos que a formação profissional para a sociedade atual deve considerar não só o conhecimento técnico, mas também, outras potencialidades do trabalhador, vendo-o como um ser em constante construção, capaz de comprometer-se com a transformação social.

Na presente pesquisa, a formação profissional na sociedade atual apareceu como ponto importante para todos os sujeitos investigados, sendo apontada como algo fundamental ao mundo que apresenta diariamente novas demandas e novas formas de trabalho. Ao mesmo tempo em que mencionam a existência de uma ordem mundial na qualificação profissional do trabalhador dos dias atuais, os sujeitos pesquisados apontam também outro aspecto relevante que é a necessidade de um ensino de qualidade no processo de formação do trabalhador.

Para comprovar essa afirmação trazemos na Tabela 1. a fala de alguns alunos, nominando-os por letras do Alfabeto, a fim de preservar suas identidades:

Vale destacar que participaram dessa conversa um grupo de sete alunos, sendo três do sexo feminino e quatro de sexo masculino, porém o Aluno "B" e o aluno "E" não quiseram explanar sua fala, apenas responderam que concordavam com o colega que lhe antecedeu, pois também pensavam como eles. O Aluno "F" posicionou-se de forma muito semelhante ao Aluno "G".

Para os cinco tutores que responderam ao questionário, essa categoria é apontada na Tabela 2 .

Ao analisar as falas dos sujeitos dessa pesquisa, per- 
FORMAÇÃO PROFISSIONAL NA SOCIEDADE ATUAL: ACEPÇÕES DOS PROTAGONISTAS DO CURSO TÉCNICO EM SEGURANÇA DO TRABALHO DO IFCE NA MODALIDADE A DISTÂNCIA

Tabela 1: Visão dos alunos sobre a Formação Profissional na sociedade atual

\begin{tabular}{|c|c|}
\hline Sujeitos & O que dizem? \\
\hline ALUNO “A” & $\begin{array}{c}\text { A formação profissional tem que ser com muita qualidade.(...) Porque } \\
\text { o número de cursos ofertados em várias áreas é grande, (daqui pra } \\
\text { Fortaleza só o que tem é anúncio: curso técnico nisso, } \\
\text { naquilo...) e não é só o certificado que vai lhe inserir no } \\
\text { mercado de trabalho, mas sim a qualidade da formação. (...) }\end{array}$ \\
\hline ALUNO “C” & $\begin{array}{l}\text { E eu acho que essa sociedade em relação ao passado, mudou e hoje a } \\
\text { gente tem como se preparar melhor. }\end{array}$ \\
\hline ALUNO “D” & $\begin{array}{l}\text { Realmente é pela educação que tem que preparar o profissional para a } \\
\text { sociedade, não há outro meio. Mas também não é só ofertar } \\
\text { curso profissionalizante, deve ofertar também a oportunidade da } \\
\text { pessoa praticar aquilo, porque oferecer só instrução sem a } \\
\text { pessoa ter prática, dificilmente ela entra no mercado. (...) }\end{array}$ \\
\hline ALUNO “G” & $\begin{array}{c}\text { Eu vejo que a sociedade exige cada vez mais dos alunos, do homem. Exige } \\
\text { qualificação, que você tenha um currículo cada vez melhor, para } \\
\text { poder exercer (as funções) dentro de uma sociedade cada vez mais } \\
\text { competitiva. }\end{array}$ \\
\hline
\end{tabular}

cebemos uma sintonia entre o que estes apontam e o que nos mostram alguns dos pesquisadores citados no decorrer desse texto, dentre eles Lima, Alcoforado e Marinelli (2012), quando relatam sobre a necessidade gerada, a partir da expansão do capitalismo, de universalizar a escola como agente social de preparação para a inserção no mundo do trabalho. Inferimos, nas declarações dos investigados, a percepção de que a sociedade entrou no processo de modernização tecnológica e organizacional e, dentro desse processo, a necessidade de mão de obra qualificada torna-se cada vez mais imperativa no sistema capitalista mundial.

Constatamos assim, que a ideia de "Formação Profissional de Qualidade" para estes sujeitos está diretamente associada ao papel da instituição escolar como agente formador. Nas falas dos alunos isso fica mais evidente quando afirmam que o conhecimento é a principal exigência da sociedade atual, dando-nos a entender que o local mais indicado para encontrar esse conhecimento é na instituição educacional. Quando falam da Formação Profissional, apontam de modo específico, projetos que compõem a atual política educacional do Brasil, considerando estes, uma medida adequada, porém reconhecendo que ainda há muita coisa a ser feita. Ilustramos essa constatação com as falas destes alunos:

(...) mais ou menos, há dezoito anos atrás, pra você entrar numa universidade pública tinha que se matar de estudar ou você estudava ou você não passava e até pra entrar numa faculdade particular era difícil por que era muito cara. Hoje não, hoje em dia tem PROUNI, tem quotas, tem SISU que facilita a entrada na universidade, tem SISUTEC, da área técnica de graça, abrem vagas no SENAC, tem vantagem mil. (Aluno "D")

(...) Mas também vejo que não há só flores, há também muitos pontos fracos. Por exemplo: nós somos alunos desse sistema a Distância e o governo, apesar de oferecer vários cursos, oportunidades como o PROUNI, como o SISUTEC, dá pra gente, mas o importante não é só oferecer, tem que ter estrutura, dar condições pra que o aluno permaneça no curso.(...) O caminho é o estudo, o caminho é a qualificação profissional, mas os alunos também têm que cobrar das instituições públicas uma melhor qualidade no ensino. (Aluno "G")

Embora haja o reconhecimento de que o acesso à formação profissional foi possibilitado, a ânsia pela qualidade no processo de formação é perceptível. E considerando que boa parte das instituições responsáveis por esta formação é de natureza pública, os alunos entendem ser preciso investir nessa qualidade, como forma de garantir não só a permanência do aluno na formação, mas, sobretudo, a sua inserção bem sucedida no mundo trabalho. Se isto não acontece, as políticas de formação profissional não estão cumprindo o seu papel na sociedade brasileira.

Em relação ao pensamento dos professores pesquisados, a maioria deles apresenta uma fala mais sucinta que a dos alunos e tutores e, ao mesmo tempo, com opiniões divergentes entre si, sobre a categoria em análise. Assim se expressam:

A relação entre o homem e a sociedade nos dias 
FORMAÇÃO PROFISSIONAL NA SOCIEDADE ATUAL: ACEPÇÕES DOS PROTAGONISTAS DO CURSO TÉCNICO EM SEGURANÇA DO TRABALHO DO IFCE NA MODALIDADE A DISTÂNCIA

Tabela 2: Visão dos tutores sobre a Formação Profissional na sociedade atual

\begin{tabular}{|c|c|}
\hline Sujeitos & O que dizem? \\
\hline \multirow{4}{*}{ Tutor 1} & Na sociedade hoje existe um somatório de troca de conhecimentos e a \\
\hline & Formação Profissional, dentro desse contexto, é um diferencial de qualidade constante. \\
\hline & A sociedade avança numa procura de modernização e globalização, e \\
\hline & o homem nem sempre está preparado para acompanhar tal avanço. (...) \\
\hline \multirow[t]{3}{*}{ Tutor 2} & A Formação Profissional dentro desse contexto social é mais que \\
\hline & $\begin{array}{l}\text { necessária. Sem uma formação qualquer o homem está, aos poucos, } \\
\text { sendo ultrapassado até mesmo nos direitos mais básicos. }\end{array}$ \\
\hline & O individualismo prevalece na sociedade. (...) Percebe-se que são \\
\hline \multirow{3}{*}{ Tutor 3} & poucos os que realmente se importam com a coletividade. A formação \\
\hline & profissional tem como objetivo modificar a realidade econômica (...) \\
\hline & e a sociedade também, pois "falta profissional capacitado". \\
\hline \multirow[b]{2}{*}{ Tutor 4} & A formação profissional pode, de certa forma, resgatar possíveis \\
\hline & $\begin{array}{c}\text { valores que foram se perdendo ao longo desse processo de } \\
\text { desenvolvimento. (...) }\end{array}$ \\
\hline Tutor 5 & $\begin{array}{l}\text { Entre o homem e a sociedade há uma relação de troca. Daí, é } \\
\text { interessante que haja sempre uma formação e/ ou qualificação na } \\
\text { área profissional para que os desafios sejam vencidos. }\end{array}$ \\
\hline
\end{tabular}

atuais é péssima e, neste contexto, a Formação Profissional deixa a desejar (Prof. 1).

\begin{abstract}
A Formação Profissional no atual contexto social é uma coisa excelente, pois promove a inclusão social (Prof. 2)

A sociedade exige cada vez a presença de homens competentes no mercado de trabalho. O mercado exige competência e quem não a tem, não se estabelece. Fica sempre à margem da sociedade. Essa competência o homem adquire através da educação e a escola é também responsável pelo desenvolvimento dessa competência. (...) Então dentro do contexto, como professor, eu digo que nós estamos formando gente, capacitando para que eles tenham oportunidade de emprego e possam trabalhar com essa competência que o mercado exige. (Prof. 3)
\end{abstract}

Vale salientar que no questionário aplicado a esses sujeitos foi perguntado o seguinte: "Como você percebe a relação homem e sociedade nos dias atuais e como entende a Formação Profissional dentro desse contexto social"?

Conforme vemos nas respostas dos professores, um deles se posiciona de modo pessimista para responder as duas coisas (Prof. 1), o outro não faz referência à relação homem e sociedade, entretanto apresenta uma visão bastante positiva sobre a Formação Profissional (Prof. 2). A fala mais detalhada e mais realista é a do Prof. 3, que nos demonstra uma visão mais crítica da sociedade capitalista, porém, acredita que, en- quanto professor da modalidade Educação Profissional, está contribuindo para a melhoria da qualidade de vida desse indivíduo/cidadão que busca a qualificação que o mercado exige. Assim como os alunos, também atribui à escola parte da responsabilidade pela formação profissional.

Constatamos, a partir dos achados, que as concepções dos diferentes sujeitos investigados nessa pesquisa acerca das nuances que perpassam essa categoria - Formação Profissional na Sociedade Atual - confundem-se com a visão de educação no seu sentido mais amplo, o que nos leva a resgatar o pensamento de Virote (2005) que concebe à escola a condição de formar o homem para o mundo do trabalho e para o exercício da cidadania, ideia que também estamos defendendo nesse estudo. Assim afirma a autora:
A escola pode assumir uma postura de enfrenta- mento do capitalismo, ao promover uma educação capaz de formar cidadãos e cidadãs, que dominem a técnica e a tecnologia e que, acima de tudo, sejam capazes de não se deixarem escravizar pelo capital Virote (2009 p. 18)

Finalizando a análise dessa categoria, ratificamos mais uma vez que, ao mesmo tempo em que vemos a escola como uma instituição a serviço do capitalismo, também a percebemos como instrumento de libertação como propõe Freire (2005), na medida em que é oferecida uma educação que cultive valores humanísticos, políticos e sociais, em detrimento do desenvolvimento de uma competência técnica. 
FORMAÇÃO PROFISSIONAL NA SOCIEDADE ATUAL: ACEPÇÕES DOS PROTAGONISTAS DO CURSO TÉCNICO EM SEGURANÇA DO TRABALHO DO IFCE NA MODALIDADE A DISTÂNCIA

Portanto, pensar numa formação profissional que seja, de fato, considerada de qualidade, é preciso que no bojo do seu currículo, perpassem outros aspectos necessários à formação integral do homem que vão além da preparação técnica, para atividades laborais. Em relação ao objeto analisado dentro dessa categoria na presente pesquisa, verificamos que já há algum direcionamento nesse sentido, porém ainda existem algumas lacunas na parte operacional do projeto do curso Técnico em Segurança do Trabalho do IFCE que impedem essa formação mais efetiva. Uma dessas lacunas refere-se aos desafios de ordem político-financeiros para desenvolver plenamente o que é planejado.

\section{CONSIDERAÇÕES FINAIS}

No que se refere à Educação Profissional na sociedade atual, evidenciamos entre os diferentes sujeitos a concepção de que a escola tem o papel de formar o homem para o mundo do trabalho e para a cidadania. Porém, nesse sentido, deve assegurar uma educação que possibilite a associação teoria e prática como forma de garantir uma aprendizagem efetiva.

A Educação Profissional de nível Técnico por meio da Educação a Distância constitui-se uma política de educação em nível nacional, entretanto ainda é evidente a burocratização e a falta de devida atenção ao bom funcionamento dessa política. Pudemos sentir de perto esta realidade, ao constatarmos a angústia da coordenação do curso investigado, ao mencionar as dificuldades que enfrenta para enviar tutores e professores aos polos de estudo, por falta de recursos financeiros.

Nesse sentido, afirmamos que o presente estudo trouxe, entre outras contribuições, a possibilidade de fomentar a discussão sobre as políticas educacionais brasileiras mais recentes em torno da Educação Profissional, especificamente em torno do Sistema e-Tec. um dos elementos constituintes de outra política ainda mais abrangente: O PRONATEC - Programa Nacional de Acesso ao Ensino Técnico e Emprego que foi criado pelo Governo Federal, em 2011, com o objetivo de ampliar a oferta de cursos de educação profissional e tecnológica no país.

\section{REFERÊNCIAS}

BOGDAN, R.; BIKLEN, S. Investigação qualitativa em educação: uma introdução à teoria e aos métodos. Porto - Portugal: Porto Editora LDA, 1994.

BRASIL. Constituição (1988). Constituição da República Federativa do Brasil. Brasília, DF, 1988.
Relatório do PARECER CNE/CEB No 15/98.

Trata das Diretrizes Curriculares Nacionais para o Ensino Médio. Brasília - DF, 1998.

Decreto 5.154 de 23 de julho de 2004 . Regulamenta o parágrafo $2^{\circ}$ do art. 36 e os artigos 39 a 42 da LDB 9394/96. Brasília - DF, 2004.

MEC/PROEP/SEMTEC. Proposta de Políticas Públicas para a Educação Profissional e Tecnológica. Brasília - DF, 2004.

Decreto $n^{\circ} 2.208$, de 17 de abril de 1997. In: Educação Profissional e Tecnológica - Legislação Básica. 6. ed. Brasília: DF, 2006.

Ldb fácil: leitura crítico - compreensiva, artigo a artigo. In: CARNEIRO, M. A. (Ed.). Lei de diretrizes e bases da educação nacional. Lei $n^{\circ}$ 9394/96, de 20 de dezembro de 1996. Petrópolis: Vozes, 2011.

CATAPAN, A. H.; KASSICK, C. N.; OTERO, W. R. I. Currículo Referência para o Sistema e-Tec Brasil: uma construção coletiva. Florianópolis: PCEADIS/CNPq/Universidade Federal de Santa Catarina, 2011.

FREIRE, P. Pedagogia do oprimido. Rio de Janeiro: Paz e Terra, 2005.

FRIGOTTO, G. Educação e crise do capitalismo real. 2. ed. São Paulo: Cortez, 1996.

GIL, A. C. Como elaborar projetos de pesquisa. 5. ed. São Paulo: Atlas, 2010.

KRUPPA, S. M. P. Economia Solidária e Educação de Jovens e Adultos. Brasília. [S.1.]: Inep, 2005. P. 104.

LIMA, F. d. C. S. O novo paradigma técnico produtivo e a qualificação do trabalhador. In: SOUSA, A. A.; OLIVEIRA, E. G. D. (Ed.). Educação profissional e análise contextualizada. Fortaleza: CEFET-Ce, 2005.

LIMA, M. A. M.; ALCOFORADO, J. L. M.; MARINELLI, M. Educação e trabalho: uma análise crítica da educação profissional no brasil. In: SANTOS, A. N. d.; TAHIM, A. P. V. d. O.; MARINHO, G. S. (Ed.). Educação: Perspectivas e Reflexões contemporâneas. Fortaleza: Edições UFC, 2012.

MORAES, L. S.; DIAS, A. M. I.; NASCIMENTO, I. V. Currículo organizado por competência e o redesenho curricular dos cursos técnicos. In: ALBUQUERQUE, L. B. (Ed.). Cultura, currículos e identidades. Fortaleza: Editora UFC, 2004. 
OLIVEIRA, E. G. Novos caminhos na educação profissional brasileira? In: SOUSA, A. A. (Ed.).

Educação Profissional: análise contextualizada.

Fortaleza: CEFET-CE, 2005.

PACHECO, E. Institutos federais: uma revolução na educação profissional e tecnológica. São Paulo: Moderna, 2011.

Perspectivas da educação Profissional técnica de nível médio: Proposta de Diretrizes curriculares nacionais. São Paulo: Moderna, 2012.

PERRENOUD, P. Construir as competências desde a escola. Porto Alegre: Artes Médicas, 1999.

TUON, L. PIB de 2012 confirma queda do Brasil no ranking das maiores economias. Revista Veja on-line de 01/03/2013. 2013. Disponível em: <http://veja.abril.com.br/noticia/economia/ pib-de-2012-confirma-queda-do-brasil-no-ranking/ -das-maiores-economias> Acesso em: 02 Dez. 2013.

VIROTE, S. M. P. A educação profissional técnica de nível médio integrada ao ensino médio: implicações das mudanças legais no governo Lula para o IFG. Dissertação (Mestrado) - Pontifícia Universidade Católica de Goiás, 2009. Disponível em: <http: //cefetgo.br/observatorio/images/downloads/projetos/ a_educacao_profissional_tecnica_nivel_medio.pdf>. Acesso em: 02 Jul. 2013. 